\title{
BLOG@CACM
}

The Communications Web site, http://cacm.acm.org, features more than a dozen bloggers in the BLOG@CACM community. In each issue of Communications, we'll publish selected posts or excerpts.

Follow us on Twitter at http://twitter.com/blogCACM

Eyes Forward

Mark Guzdial considers why computing education lags

behind other sciences, while Daniel Reed weighs balancing immediate research needs against future uncertainty.

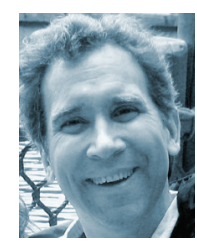

Mark Guzdial "We May Be 100 Years Behind in Making Computing Education Accessible to All"

http://cacm.acm.org/ blogs/blog-cacm/171475-we-may-be100-years-behind-in-making-computingeducation-accessible-to-all/fulltext

January 17, 2014

Just how far behind other STEM disciplines are we in computing education? Unlike mathematics and the sciences, we do not have teachers in every school. We do not have a wide range of well-defined, standards-based curricula for elementary and primary levels with supportive materials available to every teacher. In the U.S., there are few pre-service teacher professional development programs available at schools of education, and few states can offer a credential or license to teach that says computer science teacher. How long does it take to build up all that stuff?

Here is one way of measuring the gap:

- The National Council of Teachers of Mathematics (NCTM) is the professional organization of mathematics teachers and administrators in the U.S. It was formed in 1920.
- The American Association of Physics Teachers (AAPT) is the professional organization for physics teachers in the U.S. It was formed in 1930.

- The Computer Science Teachers Association (CSTA) was formed in 2005.

The gap may be more than 75 or 85 years, though, because NCTM and AAPT were formed when much of the school infrastructure was already created. There were physics and mathematics teachers in most schools in the U.S. when AAPT and NCTM were formed. There were physics education and mathematics education faculty helping prepare the next generation of teachers already. We in computing education do not have those advantages even today.

It is worth considering what that presence in schools buys those other disciplines. Why would we want to be in school anyway? One of the explicit roles for schools in the U.S. (and probably many other nations) is to ensure equal access. The first item in the mission of the U.S. Department of Education is to "Strengthen the Federal commitment to assuring access to equal educational opportunity for every individual." Thomas Jefferson argued the purpose of public schools was to "diffuse knowl- edge more generally through the mass of the people." We want computing education to be in schools to give everyone the opportunity to pursue computer science.

Computer science education today is mostly accessed by males who are white or Asian. My wife and colleague, Barbara Ericson, has been getting a significant amount of press for her analysis of the results of the AP CS exam in 2013. There were three states in which no females took the exam. USA Today had a stunning visualization of just how more gender-skewed CS is compared to all other AP exams. In 11 states, no black students took the exam. In eight states, no Hispanic students took the exam. Yahoo News had an amusing piece where they pointed out that kids of Wyoming might be underrepresented in CS- not a single student took the exam in that state. CS is not fully accessible in schools yet.

When I talk to my colleague computer scientists about how far behind we are, they sometimes suggest the way to close the gap is to "create an alternative system." They suggest we build a computing education system built around "city recreation departments, after-school programs," and programs like Khan Academy and MOOCs. Certainly, building an alternative education program, especially one wholly or significantly online, is an important and interesting research endeavor. But rebuilding an entire education system as a shortcut to getting one subject into schools seems unlikely to be easier or shorter.

Chris Stephenson pointed out in her blog post (http://bit.ly/1nuCjca) 
that university CS faculty do not understand what schools do and how they do it. What is worse, I fear computer scientists do not understand the necessity of traditional face-to-face schools for providing access. Students who know about computing and have the resources to succeed at it are frequently privileged (see Philip Guo's excellent post on what technical privilege means, at http://bit.ly/1bNlUua). As seen in the recent University of Pennsylvania study of MOOCs, students who succeed at MOOCs tend to already be well educated. Most people, especially underprivileged students, need a teacher today. Being able to reach an online education resource is not the same as access if you need a teacher and the infrastructure of school to help you understand.

Someday, we might provide students online supports that are equivalent to an in-person teacher. That is a research goal. Today, we do not know how to make a new school framework that still achieves the goal of giving everyone access. Today, if we want more people to have access to computer science education, we need face-toface schools and in-person teachers. We need to work within the existing school framework to make that happen. And we have a long way to go.

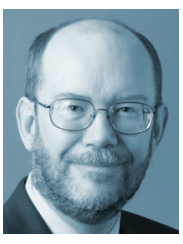

Daniel Reed "Deferred Maintenance on the Future"

http://cacm.acm.org/ blogs/blog-cacm/171143deferred-maintenance-onthe-future/fulltext

January 6, 2014

In straitened financial times, time horizons shrink. This observation is self-similar across scales, applying equally to individuals and families, small businesses and corporations, and countries and economic blocs. If you find yourself struggling to pay bills, even after eliminating luxuries, then you defer some purchases, often painfully. Indeed, if you are homeless, cold, and hungry, physical needs shrink time to the here and now - the next meal and a warm place to sleep trump all else. That is something worth remembering about those less fortunate as we face a near-record cold across much of the continental U.S.
When times are difficult, as an individual, you keep driving that aging car or truck, even as its reliability declines and the risks of major failure increase. As a small business owner, you defer that infrastructure upgrade, making do with what you have. As a CEO, you avoid risks, focusing on expense reduction and weathering the financial storm. As a country, you collectively focus on the short term, avoiding or militating the effects of recession, prioritizing short-term expenditures over long-term investments.

These sacrifices are natural and rational-in the short term. If continued too long, however, they ultimately lead to calamity and loss, as individuals suffer, infrastructure fails, and the future becomes shrouded in a miasma of unfulfilled dreams. For all our physical wants and needs, we are creatures of dreams.

Make no mistake; balancing the immediate, pressing, and real needs of the here and now against the uncertain and ill-defined future is a difficult task, made no easier by a cacophony of competing petitioners, each with compelling arguments and considerable needs. Yet it is precisely such a time when wisdom and foresight are required; it is the very definition of leadership. Although the needs of the present are real, dreams of the future must not be sacrificed on the altar of exigency.

\section{Telling the Future the Past}

Today in the U.S. we face difficult challenges, with a growing backlog of deferred intellectual maintenance. Overworked and sleep-deprived drivers are steering many of our vehicles of discovery on balding tires across potholed roads. Stripping away the metaphor, we are struggling to sustain appropriate investments in basic research infrastructure and facilities operations, and our dispirited researchers face ever-diminishing odds of research funding as they work to keep laboratories operational and students and post-doctoral research associates funded.

It is worth remembering that the Computer Science and Telecommunications Board (CSTB) of the U.S. National Academies released and updated the famous "tire tracks" diagram (http://bit.ly/1bYhSlK) illustrating the path from basic computing research ideas to major industries. In almost every case, the time from discovery to major societal impact was a decade or more, yet few could have imagined that impact at the time of discovery.

Today's ubiquitous smartphone or tablet has its roots in Engelbart's 1968 "mother of all demos" (http://bit. ly/1lEdNGe), and a host of other advances in microprocessors, memory and storage systems, Web services, and wired and wireless broadband communications. The same is true of cloud computing, advanced robotics, streaming multimedia, global positioning systems, and supercomputing. Each capability is the evolving outgrowth of decades of basic and applied research by tens of thousands of dedicated and passionate researchers. Their dreams of what might be became the computing and communications infrastructure that underpins today's society.

The impact of basic research is no less profound in a host of other domains, and today's choices have longterm implications for national and international competitiveness. As history has repeatedly shown, investment in the future-basic researchis integral to economic recovery and long-term growth. Yet by its very definition, the intellectual and pragmatic outcomes of specific research projects and directions are unpredictable. It is only in retrospect that we see the clear and unmistakable benefits - in medicine and public health, in design and manufacturing, in energy production and efficiency, and yes, in computing and communications.

\section{The Road Ahead}

The past speaks urgently to the present about the future. It whispers about what could be, about dreams deferred and opportunities lost, about innovation and economic success, and about creativity.

It is time to put some new tires on the vehicle of scientific discovery and head out to the future. As Kerouac noted in On the Road, there's "Nothing behind me, everything ahead of me, as is ever so on the road." We do not know what we will find, but the journey itself is the destination. It leads to the future and a better world.

\footnotetext{
Mark Guzdial is a professor at the Georgia Institute of Technology. Daniel Reed is Vice President for Research and Economic Development at the University of Iowa.
}

(C) 2014 ACM 0001-0782/14/04 \$15.00 